\title{
Stigma and Help Seeking for Mental Health Among College Students
}

\author{
Daniel Eisenberg \\ University of Michigan, Ann Arbor \\ Marilyn F. Downs \\ Tufts University, Medford, Massachusetts \\ Ezra Golberstein \\ Harvard Medical School, Boston, Massachusetts \\ Kara Zivin \\ Department of Veterans Affairs and University of Michigan, Ann Arbor
}

\begin{abstract}
Mental illness stigma has been identified by national policy makers as an important barrier to help seeking for mental health. Using a random sample of 5,555 students from a diverse set of 13 universities, we conducted one of the first empirical studies of the association of help-seeking behavior with both perceived public stigma and people's own stigmatizing attitudes (personal stigma). There were three main findings: (a) Perceived public stigma was considerably higher than personal stigma; (b) personal stigma was higher among students with any of the following characteristics: male, younger, Asian, international, more religious, or from a poor family; and (c) personal stigma was significantly and negatively associated with measures of help seeking (perceived need and use of psychotropic medication, therapy, and nonclinical sources of support), whereas perceived stigma was not significantly associated with help seeking. These findings can help inform efforts to reduce the role of stigma as a barrier to help seeking.
\end{abstract}

Keywords: stigma; help seeking; mental health; college students

$\mathrm{T}$ he majority of adults with mental disorders in the United States do not receive mental health care (Wang, Lane, et al., 2005) despite the availability of evidence-based treatment (U.S. Department of Health and Human Services, 1999). Those who do receive services often delay seeking help or do not adhere to recommended treatment (Sirey, Bruce, Alexopoulos, Perlick, Raue, et al., 2001; Wang, Berglund, et al., 2005). These low rates of treatment for mental disorders are evident in all age groups (U.S. Department of Health and Human Services, 1999).

Authors' Note: This article, submitted to Medical Care Research and Review on January 3, 2009, was accepted for publication on March 2, 2009.

Please address correspondence to Daniel Eisenberg, Department of Health Policy and Management, University of Michigan, M3517, SPH II, MC 2029, 109 S. Observatory Rd., Ann Arbor, MI 48109-2029; e-mail: daneis@umich.edu. 
Reducing barriers to help seeking has particular significance in college student populations, for several reasons. Approximately three quarters of lifetime mental disorders have first onset by age 24 (Kessler et al., 2005), and about half of American youth attend postsecondary education (National Center for Education Statistics, 2008a). Mental health problems early in life are associated with adverse academic, occupational, health, and social outcomes (Breslau, Lane, Sampson, \& Kessler, 2008; Ettner, Frank, \& Kessler, 1997; Kessler, Walters, \& Forthofer, 1998), suggesting that timely and effective treatment may offer substantial long-term benefits. Colleges provide a unique opportunity to identify, prevent, or treat mental disorders because campuses often encompass students' residences, social networks, and many services.

\section{Conceptual Framework}

Basic models of help seeking for health problems provide a useful framework for understanding factors that affect decisions to seek mental health care. These models commonly describe help seeking as a multistage process comprising several interrelated behaviors (Mechanic, 1966). Broadly speaking, individuals experience a health problem, perceive a need for professional help, evaluate the costs and benefits of receiving treatment (within the context of social norms regarding seeking help), and take action to receive care by choosing one of several types of help for mental health problems.

In these conceptual models, beliefs and attitudes about mental illness and treatment are likely to influence an individual's propensity to perceive a need for help as well as an individual's assessment of the costs and benefits of receiving treatment (and consequently whether the individual pursues treatment). Stigma associated with mental illness has been identified as a key attitudinal factor that may impede mental health service use, and stigma reduction is a central objective of national mental health policies (Hogan, 2003).

Although the term mental illness stigma is often used in a broad sense, it takes several distinct forms. Public stigma is defined as negative stereotypes and prejudice about mental illness (such as "people with mental illness are dangerous and unreliable") held collectively by people in a society or community (Corrigan, 2004). Public stigma can be thought of as the aggregate of each individual's stereotypes and prejudices, which we refer to in this article as personal stigma (as in Griffiths, Christensen, Jorm, Evans, \& Groves, 2004). An individual's perception of public stigma is commonly referred to as perceived public stigma (Corrigan, 2004). Finally, self-stigma occurs when an individual identifies himself with the stigmatized group (people with mental illness, in this context) and applies corresponding stereotypes and prejudices to the self.

Corrigan, Watson, and Barr (2006) propose that for an individual, these concepts of stigma often develop sequentially once public stigma is present. An individual 
becomes aware of public stigma (i.e., perceived public stigma), then forms personal attitudes (i.e., personal stigma) that may or may not concur with perceived stigma; and then determines whether or not to apply these stigmatizing attitudes to the self (self-stigma).

Numerous studies document high levels of public stigma related to mental illness (Phelan, Link, Stueve, \& Pescosolido, 2000), suggesting that stigma could be a formidable barrier to help seeking. Perceived public stigma may hinder people from using mental health services to avoid possible criticism or discrimination from others. Personal stigma and self-stigma may deter individuals from seeking help if service use implies acknowledgement of one's own mental health problems and if the individual's negative attitudes about people with mental health problems would harm her own self-esteem (Corrigan, 2004).

In this study, we focus on two specific components of stigma: perceived public stigma and personal stigma. We examine personal stigma rather than self-stigma because the former is broader in the sense that it applies to everyone, regardless of whether one acknowledges having a mental health problem. Because college students often experience first onset and are unaware that they have mental disorders that would benefit from treatment (Eisenberg, Golberstein, \& Gollust, 2007), it is important to consider how stigma affects individuals who do not necessarily identify themselves as having a mental health problem.

\section{Previous Studies on Stigma and Help Seeking}

Several empirical studies have explored how mental illness stigma relates to helpseeking attitudes and behavior. Studies examining people's own stigmatizing attitudes have generally found that higher personal stigma is associated with lower help seeking among both adults (Cooper, Corrigan, \& Watson, 2003) and adolescents (Penn et al., 2005). Another study found that participants who reported embarrassment associated with mental health treatment were less likely to perceive a need for help or use mental health services, although this study did not distinguish between personal stigma or perceived public stigma (Mojtabai, Olfson, \& Mechanic, 2002).

In contrast, results have been mixed for studies that focus on perceived public stigma. Studies with clinical samples have found that higher perceived stigma is associated with lower treatment adherence and premature termination (Sirey, Bruce, Alexopoulos, Perlick, Friedman, et al., 2001; Sirey, Bruce, Alexopoulos, Perlick, Raue, et al., 2001). One community-based study found that one in four people who perceived a need for help did not seek services in part because of concerns about what others might think (Kessler et al., 2001). Another study found that both selfstigma and perceived public stigma negatively predicted help-seeking attitudes, although the focus was on intentions to seek help rather than actual behavior (Barney, Griffiths, Jorm, \& Christensen, 2006). On the other hand, results from a longitudinal community-based study in Australia found no correlation between perceived public stigma and mental health service use (Jorm et al., 2000). Similarly, a 
recent study of college students found that perceived public stigma was not associated with past-year service use (Golberstein, Eisenberg, \& Gollust, 2008).

\section{Research Questions}

We addressed two specific research questions. First, what are the levels of perceived and personal stigma among college students? Within this first question, we examined how levels of perceived and personal stigma compare and which characteristics of students were associated with higher or lower stigma. Second, what is the association between help seeking and these two types of stigma? Within this second question, we examined a range of help-seeking variables, including perceived need for help, use of psychotropic medication, use of therapy or counseling, use of support for mental health from nonclinical sources, and willingness to talk to academic personnel about mental health problems that affect performance in school. We hypothesized that both perceived and personal stigma would be independently associated with lower help-seeking behavior under the assumption that an individual is influenced by both others' and his own attitudes regarding mental health treatment.

\section{New Contributions}

Within the literature on stigma and mental illness, this is the first empirical study to our knowledge to (a) investigate how both perceived public stigma and personal stigma are independently associated with help-seeking behavior, (b) make a direct comparison between levels of perceived and personal stigma, and (c) examine stigma and help seeking using a multicampus, random sample of college students. Disentangling the relative contributions of these aspects of stigma can improve understanding of how stigma may affect discrete steps in the help-seeking process. This can inform the development of stigma reduction efforts that are more effectively tailored to increase help-seeking behavior among diverse sectors of the college student population.

\section{Methods}

\section{Sample}

In fall of 2007, we conducted an online survey of college students about a range of mental health topics. The survey study was advertised widely to colleges and universities nationwide. The only inclusion criterion was that participating institutions were required to contribute their share of the cost of the study (and in return they received a detailed report and complete data set for their students). In all, 13 schools participated: California State University, Chico, Emory University, Miami University of Ohio, New Mexico State University, Penn State University, Tufts University, 
University of Michigan, University of North Carolina-Chapel Hill, University of North Carolina-Greensboro, University of Illinois-Springfield, University of IllinoisChicago, University of Illinois-Urbana Champaign, and Yeshiva University. This group of schools is diverse in geography (at least two from each census region), public/private nature (10 public, 3 private), demographics (the median school is $34 \%$ non-White; range is $0 \%$ to $63 \%$ ), enrollment size (median is 16,000 ; range is 5,000 to 43,000 ), and graduation rate (median is $82 \%$; range is $37 \%$ to $92 \%$ ). These median characteristics are similar to the national medians for institutions granting master's and doctoral degrees (National Center for Education Statistics, 2008b).

At each institution, we randomly selected 1,000 students from the full population, including both undergraduate and graduate students. We recruited these students with a mailed letter introducing the survey and including a $\$ 1$ bill as a token of appreciation, and we followed with e-mail reminders linking to the online survey. In these communications, we also informed the students that they were entered into a sweepstakes for cash prizes regardless of their participation. Of the 13,000 recruited students, 5,689 completed the survey (3,962 undergraduates and 1,727 graduate students), yielding a $44 \%$ participation rate. A small number of students had missing responses for the stigma scales or other key measures, leaving 5,555 $(43 \%)$ with complete data for the purpose of this study.

\section{Accounting for Survey Nonresponse}

Given that high survey response rates are increasingly rare (Galea \& Tracy, 2007; Porter \& Umbach, 2006), survey methodology experts recommend investigating differences between responders and nonresponders to the extent possible (Groves, 2006). In this study, we obtained information about nonresponders from universities' administrative data, including sex, race/ethnicity, academic level, and grade point average (available at some but not all institutions). We used the administrative data to construct response propensity weights, equal to one divided by the estimated probability of response, which was estimated in a logistic regression as a function of sex, race/ethnicity, academic level, and grade point average. These weights ensure that our analysis is at least representative in terms of these variables.

In addition, to assess how nonresponse relates to mental health, we conducted a brief nonresponse survey with key mental health measures: the first two items of the Patient Health Questionnaire for depression and two questions about mental health service use. For this nonresponse survey, we randomly selected 500 nonresponders from the main survey. We recruited these students immediately following the close of the main survey, using an introductory letter with $\$ 5$, followed by e-mail and phone contact. Although this survey only achieved a $36 \%$ response rate, the data suggested that nonresponders to the main survey were somewhat less likely to have depressive symptoms and use mental health services (e.g., $11 \%$ used therapy in the previous year as compared with $14 \%$ of responders to the main survey), which is 
consistent with findings about nonrespondents in a previous study of college student mental health (Eisenberg et al., 2007).

\section{Measures}

\section{Stigma}

We measured perceived public stigma using an adaptation of the DiscriminationDevaluation (D-D) Scale developed by Link and colleagues, which has been used in several previous studies (Link, 1987; Link, Cullen, Struening, Shrout, \& Dohrenwend, 1989). The D-D scale asks people how much they agree with each of 12 statements that begin with "Most people believe ..." or "Most people think . . .," or "Most people would ..." followed by a stereotype, example of discrimination, or the opposite (an accepting view or behavior). The original D-D scale refers to a "mental patient" or a "former mental patient" or a person "who has been hospitalized for mental illness." We adapted the wording to refer instead to "a person who has received mental health treatment" because our objective was to measure perceived stigma regarding a broader concept of mental health treatment (rather than institutional treatment for severe mental illness per se). As in the original D-D scale, the answer choices were on a 6-point Likert scale: strongly agree, agree, somewhat agree, somewhat disagree, disagree, strongly disagree. As in the original use of the scale, we constructed an index of perceived stigma by coding each response as 0,1 , $2,3,4$, or 5 (with higher numbers referring to answers indicating higher perceived stigma) and calculating the average across the 12 items for each individual. We found a high internal reliability (Cronbach's $\alpha=.89$ ) in this adapted scale.

To measure people's own stigmatizing attitudes about mental health treatment or what we are referring to as personal stigma, we adapted three items from the perceived stigma scale by replacing "Most people" with "I." These three items referred, respectively, to a negative attitude (“. . . would think less of someone . .."), an accepting behavior (“. . . would accept as a close friend ..."), and an accepting attitude (". . . think someone is just as trustworthy . .."). We constructed an index of personal stigma by averaging across the three items on a 0 to 5 scale, where higher numbers refer to higher stigma, as we did for perceived stigma. The internal reliability of this scale was relatively high (Cronbach's $\alpha=.78$ ). All respondents were asked both the perceived stigma and the personal stigma items, and to balance potential ordering effects the order of the two measures in the survey was randomized. The complete wording of the measures is shown in the appendix.

\section{Help Seeking}

We measured perceived need for help by asking respondents, "In the past 12 months, did you think you needed help for emotional or mental health problems such as feeling 
sad, blue, anxious or nervous?" Mental health services use was measured with separate items asking respondents whether they took any psychotropic medications and whether they received any therapy or counseling for their mental or emotional health in the past 12 months. The above items were taken from the questionnaire used in the Healthcare for Communities Study (Wells, Sturm, \& Burnam, 2003), a national study of mental health care use.

We also included two measures of help seeking from nonclinical sources. First, we asked, "In the past 12 months have you received counseling or support for your mental or emotional health from any of the following sources? (Check all that apply)," where the answer categories were "Friend," "Family member," "Religious counselor or other religious contact," "Support group," "Other non-clinical source (specify)," and "None of the above." We coded this measure as 0 if "None" was selected and 1 otherwise. Second, we asked, "If you had a mental health problem that you believed was affecting your academic performance, which people at school would you talk to? (Check all that apply)," where answer categories were "Professor from one of my classes," "Academic advisor," "Another faculty member," "Teaching assistant," "Student services staff," "Dean of Students or Class Dean," "No one," and "Other (specify)." We coded this measure as 0 if "No one" was selected and 1 otherwise.

\section{Mental Health}

Depressive and anxiety disorders were measured with the Patient Health Questionnaire, which screens for current major depression, other depression (less severe depression such as depression not otherwise specified or dysthymia), panic disorder, and generalized anxiety disorder (Spitzer, Kroenke, \& Williams, 1999). Other covariates in our analyses included gender, age dummies (18-22, 23-25, 26-30, 31 or over), race/ethnicity dummies (Asian, Black, Hispanic, Multiple categories, Other, and White, non-Hispanic), a dummy for international student status, religiosity dummies (not at all, not too, fairly, or very religious), sexual orientation dummies (heterosexual, gay/lesbian, bisexual), dummies for category of current financial situation (struggle, tight but doing fine, not a problem), and financial situation while growing up (poor, enough but not many extras, comfortable, well-to-do).

\section{Statistical Analysis}

We tested for unadjusted differences in mean levels of stigma across subgroups using $t$ tests. We used multivariable linear regressions to estimate independent correlates of stigma, and we used multivariable logistic regressions to estimate independent correlates of binary help-seeking variables. For each regression, we allowed for clustering of standard errors within schools, and we also examined in sensitivity analysis whether the results changed when school dummy variables were included 
Table 1

Sample Characteristics $(N=\mathbf{5 , 5 5 5})$

\begin{tabular}{|c|c|c|c|}
\hline Characteristics & Percentage & Characteristics & Percentage \\
\hline Female & 54.2 & Off-campus housing & 52.6 \\
\hline Age & & Campus residence hall & 30.0 \\
\hline $18-22$ & 66.0 & Fraternity or sorority house & 2.0 \\
\hline $23-25$ & 12.5 & Other university housing & 5.2 \\
\hline $26-30$ & 10.6 & Parent or guardian's home & 7.7 \\
\hline $31+$ & 10.8 & Other housing & 2.5 \\
\hline Asian/Asian American & 10.3 & Very religious & 16.6 \\
\hline Black/African American & 6.1 & Fairly religious & 36.5 \\
\hline Hispanic/Latino & 6.3 & Not too religious & 25.9 \\
\hline Multiple categories & 4.7 & Not at all religious & 21.0 \\
\hline Other category & 5.9 & Single & 52.2 \\
\hline White, non-Hispanic, non-Arab & 66.7 & Married or domestic partnership & 13.2 \\
\hline International (non-U.S. & 7.5 & Bisexual & 2.1 \\
\hline citizen or resident) & & Gay or lesbian & 2.6 \\
\hline 1st Year undergraduate & 15.6 & Heterosexual & 94.6 \\
\hline 2nd Year undergraduate & 16.8 & Current financial situation & \\
\hline 3rd Year undergraduate & 19.1 & "It's a financial struggle" & 15.1 \\
\hline 4th Year undergraduate & 17.1 & "It's tight but I'm doing fine" & 54.5 \\
\hline 5th Year or higher undergraduate & 5.1 & "Finances aren't really a problem" & 30.5 \\
\hline Undergraduate (total) & 73.7 & Financial situation growing up & \\
\hline 1st Year graduate & 8.5 & "Poor, not enough to get by" & 2.9 \\
\hline 2nd Year graduate & 7.4 & "Enough, not many extras" & 29.9 \\
\hline 3rd Year graduate & 3.0 & "Comfortable" & 59.2 \\
\hline 4th Year graduate & 1.5 & "Well-to-do" & 8.0 \\
\hline 5th Year or higher graduate & 3.0 & & \\
\hline Graduate student (total) & 23.4 & & \\
\hline
\end{tabular}

Note: Survey response probability weights were used (see Methods section). Categories do not all sum to $100 \%$ because of missing data.

(to confirm that key results were not driven simply by between-school variation). All analyses were conducted using Stata 9.2 and were weighted using the response propensity weights described earlier.

\section{Results}

The sample characteristics are shown in Table 1. The sample included $54.2 \%$ female and $45.8 \%$ male participants, and $73.7 \%$ undergraduate students and $23.4 \%$ graduate students (and 2.9\% whose academic level could not be determined). The racial/ethnic composition was 10.3\% Asian, 6.1\% Black, 6.3\% Hispanic, 66.7\% White, 4.7\% Multiple race/ethnicities, and 5.9\% Other. 
Table 2

Levels of Stigma: Overall, by Gender, and by Race/Ethnicity

\begin{tabular}{|c|c|c|c|c|c|}
\hline \multirow[b]{2}{*}{ Overall } & \multirow{2}{*}{$\begin{array}{c}n \\
5,555\end{array}$} & \multicolumn{2}{|c|}{$\begin{array}{l}\text { Perceived Public } \\
\text { Stigma }(0-5)\end{array}$} & \multicolumn{2}{|c|}{ Personal Stigma (0-5) } \\
\hline & & 2.43 & $S D=0.75$ & 1.01 & $S D=0.84$ \\
\hline Female & 3,435 & 2.41 & (Reference) & 0.91 & (Reference) \\
\hline Male & 2,116 & 2.46 & $* * *$ & 1.13 & $* * *$ \\
\hline Asian & 579 & 2.50 & $* * *$ & 1.45 & $* * *$ \\
\hline Black & 266 & 2.77 & $* * *$ & 0.93 & \\
\hline Hispanic & 302 & 2.50 & $* * *$ & 1.05 & * \\
\hline Multiple categories & 240 & 2.48 & $* *$ & 0.91 & \\
\hline Other & 290 & 2.54 & $*$ & 1.10 & $* * *$ \\
\hline White & 3,870 & 2.38 & (Reference) & 0.95 & (Reference) \\
\hline
\end{tabular}

Note: Numbers by gender and race/ethnicity do not sum exactly to the overall $N$ because of missing information (4 people for gender, 8 people for race/ethnicity). Means were calculated using survey weights. Asterisks refer to statistically significant differences from the reference group, which is the most numerous group (female for gender, White for race/ethnicity). $S D=$ standard deviation.

$* p<.10 . * * p<.05 . * * * p<.01$.

As shown in Table 2, the mean level of perceived public stigma was substantially higher (2.43) than the mean level of personal stigma (1.01), although the latter had a slightly higher standard deviation. Relative to men, women had slightly lower perceived stigma $(-0.05, p<.01)$ and lower personal stigma $(-0.22, p<.01)$. Relative to White students, all other racial/ethnic categories had higher perceived stigma. Black students had the highest mean of perceived stigma at 2.77 (as compared with 2.38 among White students; $p<.01)$. Asian students had by far the highest mean level of personal stigma, at $1.45(p<.01$, as compared with every other group). When we examined mean levels of stigma within strata defined by both race/ ethnicity and gender (not shown in table), the one notable finding was the high level of personal stigma among Hispanic male participants - 1.31 , as compared with 0.88 among Hispanic female participants $(p<.01)$.

To examine the relationship between perceived stigma and personal stigma, we did a simple scatterplot of the two variables, where each point is weighted by the number of corresponding observations (Figure 1). As expected, the two variables were positively correlated $(r=.37)$. The graph also shows an interesting asymmetry: Many students reported high perceived public stigma and low personal stigma, but almost no student reported the reverse-high personal stigma and low perceived public stigma.

In Figure 2, we illustrate a more direct comparison between perceived stigma and personal stigma. The figure shows the distribution of responses to one of the perceived stigma items ("Most people would think less of someone who has received mental health treatment") as compared with responses to the analogous personal 
Figure 1

Scatterplot of Perceived Public Stigma Versus Personal Stigma $(N=5,555)$

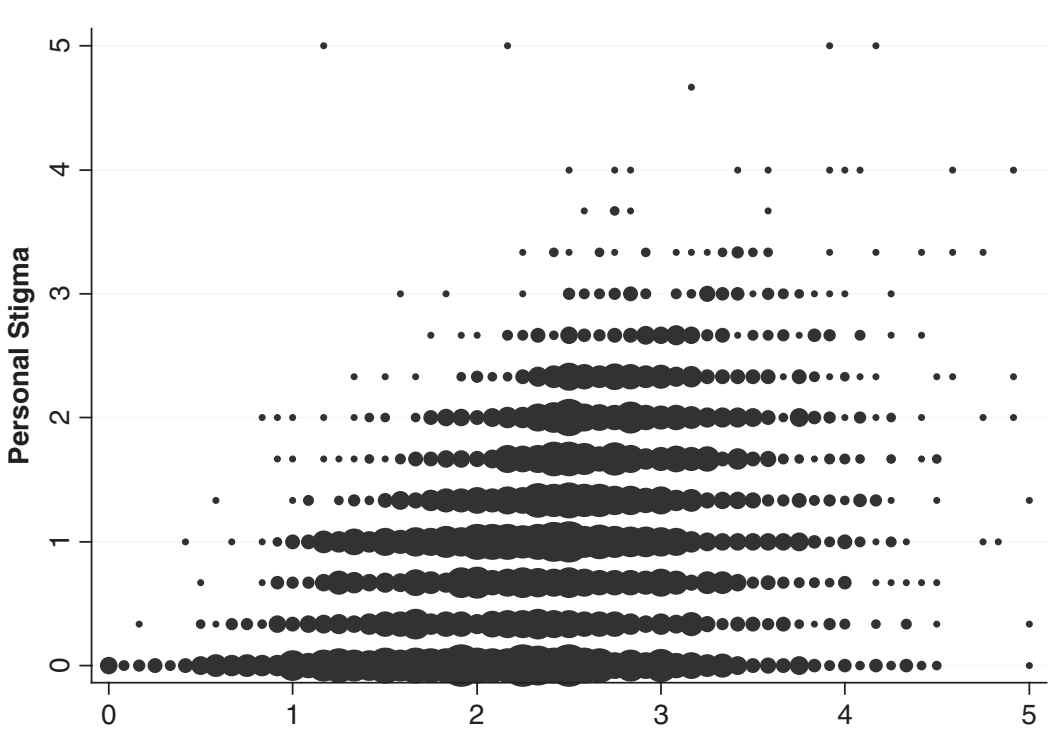

Perceived Public Stigma

Figure 2

Perceived Versus Personal Stigma

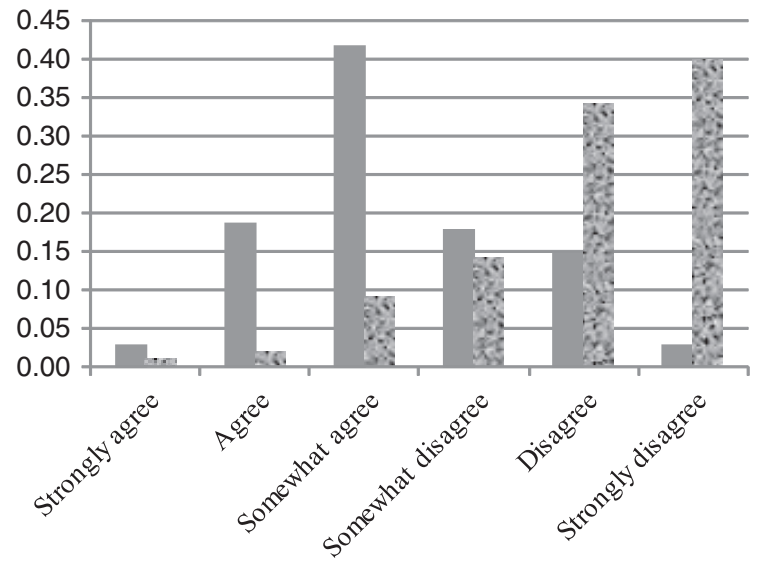

- Most people...

al... 
Table 3

Independent Correlates of Stigma

\begin{tabular}{|c|c|c|c|c|}
\hline & \multicolumn{2}{|c|}{$\begin{array}{c}\text { Perceived Public } \\
\text { Stigma }(n=5,295)\end{array}$} & \multicolumn{2}{|c|}{$\begin{array}{l}\text { Personal Stigma } \\
\quad(n=5,424)\end{array}$} \\
\hline & Coefficient & $95 \% \mathrm{CI}$ & Coefficient & $95 \% \mathrm{CI}$ \\
\hline Female & -0.07 & $(-0.12,-0.02)$ & -0.20 & $(-0.27,-0.14)$ \\
\hline Age $18-22$ & (ref) & & (ref) & \\
\hline Age $23-25$ & -0.06 & $(-0.15,0.03)$ & -0.13 & $(-0.21,-0.05)$ \\
\hline Age 26-30 & -0.07 & $(-0.15,0.02)$ & -0.14 & $(-0.21,-0.06)$ \\
\hline Age $31+$ & -0.03 & $(-0.12,0.07)$ & -0.10 & $(-0.18,-0.02)$ \\
\hline Asian/Asian American & 0.08 & $(-0.04,0.21)$ & 0.38 & $(0.31,0.44)$ \\
\hline Black/African American & 0.37 & $(0.26,0.49)$ & -0.02 & $(-0.15,0.12)$ \\
\hline Hispanic/Latino & 0.08 & $(-0.03,0.20)$ & 0.09 & $(-0.05,0.23)$ \\
\hline Multiple categories & 0.08 & $(-0.04,0.21)$ & -0.04 & $(-0.22,0.14)$ \\
\hline Other category & 0.13 & $(0.01,0.24)$ & 0.08 & $(-0.07,0.24)$ \\
\hline White, non-Hispanic, non-Arab & (ref) & & (ref) & \\
\hline International & 0.08 & $(0.00,0.16)$ & 0.32 & $(0.19,0.45)$ \\
\hline Not at all religious & (ref) & & (ref) & \\
\hline Not too religious & 0.02 & $(-0.03,0.07)$ & 0.08 & $(0.01,0.16)$ \\
\hline Fairly religious & 0.05 & $(-0.03,0.14)$ & 0.19 & $(0.13,0.25)$ \\
\hline Very religious & 0.08 & $(-0.03,0.19)$ & 0.09 & $(0.02,0.17)$ \\
\hline Bisexual & -0.03 & $(-0.24,0.18)$ & -0.22 & $(-0.41,-0.03)$ \\
\hline Gay/Lesbian & -0.06 & $(-0.18,0.07)$ & -0.23 & $(-0.39,-0.07)$ \\
\hline Heterosexual & (ref) & & (ref) & \\
\hline "It's a financial struggle" & 0.04 & $(-0.05,0.14)$ & -0.07 & $(-0.13,0.00)$ \\
\hline "It's tight but I'm doing fine" & 0.02 & $(-0.05,0.09)$ & -0.07 & $(-0.14,0.00)$ \\
\hline "Finances aren't really a problem" & (ref) & & (ref) & \\
\hline "Poor, not enough to get by" & 0.14 & $(0.02,0.27)$ & 0.16 & $(-0.13,0.45)$ \\
\hline "Enough, not many extras" & 0.11 & $(0.00,0.23)$ & 0.09 & $(-0.01,0.20)$ \\
\hline "Comfortable" & 0.08 & $(-0.01,0.17)$ & 0.06 & $(-0.05,0.17)$ \\
\hline "Well-to-do" & $(\mathrm{ref})$ & & (ref) & \\
\hline PHQ-9 depression (0-27) & 0.01 & $(0.01,0.02)$ & 0.00 & $(-0.01,0.01)$ \\
\hline Anxiety disorder on PHQ $(0 / 1)$ & -0.02 & $(-0.11,0.08)$ & -0.09 & $(-0.21,0.02)$ \\
\hline
\end{tabular}

Note: Specification: ordinary least squares with survey response probability weights and standard errors clustered by school. Sample sizes for regressions are slightly smaller than the overall sample because of missing data for covariates. $\mathrm{CI}=$ confidence interval; ref $=$ reference.

stigma item ("I $I$ would think less of someone who has received mental health treatment"). The figure shows that the majority agreed with the perceived stigma version, whereas the vast majority disagreed with the personal stigma item. This pattern was similar for the other two personal stigma items as compared with their perceived stigma analogs (results not shown).

We next examined which individual characteristics were independently associated with the two types of stigma using multivariable linear regressions (Table 3). The results show that personal stigma varied more than perceived stigma across 
Table 4

Associations Between Stigma and Help Seeking

\begin{tabular}{|c|c|c|c|c|c|c|c|c|c|}
\hline \multirow[b]{2}{*}{$\begin{array}{l}\text { Perceived } \\
\text { public } \\
\text { stigma }\end{array}$} & \multicolumn{3}{|c|}{ Perceived need } & \multicolumn{3}{|c|}{ Medication } & \multicolumn{3}{|c|}{ Therapy } \\
\hline & $\begin{array}{c}1.01 \\
(0.91 \\
1.13)\end{array}$ & & $\begin{array}{r}1.18 \\
(1.05 \\
1.32)\end{array}$ & $\begin{array}{r}0.97 \\
(0.84 \\
1.12)\end{array}$ & & $\begin{array}{r}1.17 \\
(0.99 \\
1.38)\end{array}$ & $\begin{array}{r}0.84 \\
(0.76 \\
0.94)\end{array}$ & & $\begin{array}{r}1.02 \\
(0.90 \\
1.14)\end{array}$ \\
\hline $\begin{array}{c}\text { Personal } \\
\text { stigma }\end{array}$ & & $\begin{array}{r}0.71 \\
(0.66, \\
0.76)\end{array}$ & $\begin{array}{r}0.67 \\
(0.61 \\
0.74)\end{array}$ & & $\begin{array}{r}0.61 \\
(0.54, \\
0.68)\end{array}$ & $\begin{array}{r}0.57 \\
(0.49 \\
0.67)\end{array}$ & & $\begin{array}{r}0.58 \\
(0.53, \\
0.64)\end{array}$ & $\begin{array}{r}0.57 \\
(0.51, \\
0.64)\end{array}$ \\
\hline
\end{tabular}

Note: Each column corresponds to a separate regression. Other covariates (not shown) in the regressions were the same as those in Table 2. Logistic regressions with odds-ratios and $95 \%$ confidence intervals are reported; standard errors are clustered by school.

individual characteristics. Characteristics associated with significantly higher personal stigma include younger age, being an international student, having higher levels of religiosity, and being heterosexual (as compared with gay/lesbian or bisexual). The differences by gender and race/ethnicity were similar to the unadjusted differences in Table 2. The results in Table 3 were not sensitive to alternative regression models in which we added dummy variables for each school in the sample, indicating that the differences did not simply reflect varying stigma across schools with different student characteristics. Also, we did not find significant differences in mean levels of stigma across types of schools (public versus private, higher versus lower enrollment size, and more versus less academically competitive as measured by U.S. News's reputation score).

In Table 4, we present the estimated associations between stigma and three measures of help seeking in the previous year: perceived need for help, use of psychotropic medication, and use of therapy or counseling. For each measure of help seeking, the first column shows the regression coefficient for perceived stigma when it was the only measure of stigma included; the second column shows the same for personal stigma, and the third column shows results when both measures were included. In the latter specifications, we found that personal stigma was significantly associated $(p<$ .01 ) with a lower likelihood of each measure of help seeking. The estimated odds ratios for each 1-point increase in personal stigma were not only statistically significant $(p<.01)$ but well below $1(0.67,0.57$, and 0.57 , respectively). In contrast, perceived stigma was associated with a significantly higher likelihood of perceiving a need for help $(p=.05)$ and not significantly associated with the likelihood of using medication or therapy/counseling. We also found that among students who used medication, personal stigma was associated with a lower likelihood of medicines being prescribed by a psychiatrist $(\mathrm{OR}=0.57, p<.01)$, whereas perceived stigma was not significantly associated (results not shown in table). 
Table 5

Associations Between Stigma and Nonclinical Help Seeking

\begin{tabular}{|c|c|c|c|c|c|}
\hline \multirow[b]{2}{*}{$\begin{array}{l}\text { Perceived } \\
\text { public stigma }\end{array}$} & \multicolumn{2}{|c|}{$\begin{array}{l}\text { Received Help From } \\
\text { Nonclinical Source }\end{array}$} & \multicolumn{3}{|c|}{$\begin{array}{l}\text { Would Discuss Mental Health } \\
\text { Problem With Academic Staff }\end{array}$} \\
\hline & $\begin{array}{r}0.96 \\
(0.88 \\
1.05)\end{array}$ & $\begin{array}{r}1.08 \\
(0.98 \\
1.19)\end{array}$ & $\begin{array}{r}0.85 \\
(0.75 \\
0.96)\end{array}$ & & $\begin{array}{r}0.88 \\
(0.76, \\
1.03)\end{array}$ \\
\hline Personal stigma & $\begin{array}{r}0.80 \\
(0.76 \\
0.85)\end{array}$ & $\begin{array}{r}0.77 \\
(0.72 \\
0.83)\end{array}$ & & $\begin{array}{r}0.86 \\
(0.79 \\
0.93)\end{array}$ & $\begin{array}{r}0.90 \\
(0.80 \\
1.01)\end{array}$ \\
\hline
\end{tabular}

Note: Logistic regressions with odds ratios and $95 \%$ confidence intervals are reported; standard errors are clustered by school. Each column corresponds to a separate regression. Other covariates (not shown) in the regressions were the same as those in Table 2.

We also compared reported reasons for seeking help among past-year service users (medication or therapy/counseling), between students with stigma levels above and below the median (results not shown in tables). Students with high personal stigma were less likely to report that they decided on their own to seek help $(63 \%$ as compared with $72 \%$ of students with low personal stigma; $p<.01)$. Other reported reasons for seeking help (being encouraged, pressured, or forced by a friend, family, or other person, or receiving more information about treatment options) were not significantly different between low- and high-stigma groups.

As shown in Table 5, the relationship between stigma and receiving nonclinical support for mental health was similar to that between stigma and professional mental health services in Table 4. Personal stigma was significantly associated with a lower likelihood of receiving nonclinical support $(\mathrm{OR}=0.80, p<.01)$, whereas perceived stigma was not. On the other hand, students' reported willingness to talk with academic personnel about mental health problems was negatively associated with both perceived and personal stigma, though neither estimate was significant at conventional levels ( $p=.12$ and .08 , respectively). These results remained similar across groups when we stratified the sample by past-year users and nonusers of professional mental health services (not shown in tables).

The patterns of results in both Table 4 and Table 5 remained the same under sensitivity checks in which we included school dummy variables. The results also remained similar in subgroup analyses stratified by gender and age (18-22 versus older). In addition, the results remained similar when we restricted the sample to students with an apparent disorder (positive screen for depression or anxiety) or a perceived need for help.

\section{Discussion}

In this study of a random sample of college students at 13 institutions, there were three main findings: (a) perceived public stigma was considerably higher than 
personal stigma; (b) personal stigma was elevated among certain types of students, including those with any of the following characteristics: male, younger, Asian, international, more religious, or from a poor family; and (c) personal stigma was significantly associated with several measures of lower help seeking (perceived need and use of psychotropic medication, therapy, and nonclinical sources of support), whereas perceived stigma was not significantly associated with help seeking.

The first finding may reflect a number of factors. First, respondents may have understated their true levels of personal stigma because they were unwilling to admit to others or perhaps even to themselves that they hold attitudes that may be considered socially undesirable. This social desirability bias, which is a general concern in survey research, may have been alleviated somewhat by the fact that the survey was self-administered (Nederhof, 1985). If this bias were driving the difference in reported personal versus perceived stigma, this would be notable in itself, as it would indicate an awareness and response to perceived social norms (at least in words, though not necessarily in actions). Second, students may have been thinking about society in general, more so than their fellow students, when answering the perceived stigma items referring to "most people." They might have reported lower perceived stigma if the question had specified "most of your fellow students." We did not use the latter wording, however, for two reasons: (a) We believed that the more general "most people" was more appropriate for addressing our central question of whether stigma was associated with help seeking; (b) "most people" is also consistent with the wording in the original, widely used and validated scale by Link and colleagues (Link, 1987; Link et al., 1989). Nevertheless, in future studies it would be useful to investigate whether responses differ when a more specific reference group is used.

Although these caveats are important to bear in mind, the discordance between perceived and personal stigma suggests that students have an exaggerated view of public stigma. If this is the case, campus education initiatives could focus on reducing perceived public stigma. For example, a social norms campaign could advertise the fact that $90 \%$ of students report that they would not think less of someone who has received mental health treatment. Social norms-based interventions, which aim to alter individual health-related attitudes and behaviors by correcting misperceptions about peers' behaviors and attitudes, have been widely used in campus health promotion campaigns (Wechsler et al., 2003).

In comparing perceived versus personal stigma, the asymmetry shown in Figure 1 is noteworthy. There are almost no students with high personal stigma and low perceived stigma; in other words, to have high personal stigma, one must have high perceived stigma. This seems to support the ideas that personal attitudes are significantly shaped by prevailing public attitudes (Link, 1987) and that awareness is a precursor to agreement with stereotypes (Corrigan et al., 2006). Another possible interpretation is that people with high personal stigma do not want to face cognitive dissonance associated with admitting to intolerant views that others do not hold, so they choose to assume that others share their views. 
Our estimates of sociodemographic correlates of help-seeking attitudes and behaviors are generally consistent with previous studies. For example, other studies have found that African Americans report less stigmatizing views about mental illness and mental health services (though they are also less likely to use services; Anglin, Alberti, Link, \& Phelan, 2008; Mojtabai, 2007), and Asians and Latinos generally report more negative attitudes about mental health treatment than other groups (Ojeda \& McGuire, 2006; Shea \& Yeh, 2008; Zhang \& Dixon, 2003). The fact that international students, though representing significant ethnic and cultural diversity, have generally higher personal stigma is consistent with populationbased studies indicating that U.S.-born individuals are much more likely to use mental health services (Abe-Kim et al., 2007). Regarding gender, numerous studies indicate that women have both more positive attitudes about mental health treatment and a higher likelihood of using services than men (Mojtabai, 2007; Rickwood, Deane, Wilson, \& Ciarrochi, 2005). As for age, while recent trends suggest that young adults hold more favorable attitudes than previous cohorts, young adults also endorse more stigmatizing views and use fewer services compared with older adults (Mojtabai, 2007; Ojeda \& Bergstresser, 2008). Therefore, there appear to be important differences across both age and cohorts. Collectively, these findings suggest that stigma reduction efforts on college campuses may be most effective if they are targeted and tailored to the attitudes and behaviors of specific student populations. The targeting might be accomplished, for example, by coordinating programs with student groups that are populated predominantly by students in categories with higher levels of stigma. Effective tailoring of these efforts will require additional understanding of how and why stigmatizing attitudes are different among these students.

The central finding of this study is that personal stigma was independently associated with help seeking for mental health, whereas perceived public stigma was not. It is important to keep in mind the caveat that these are not cleanly identified causal relationships. Perhaps the most likely confounding factor in this cross-sectional analysis is that causality may run in both directions. For example, personal stigma may inhibit help-seeking behavior, but at the same time, help-seeking behavior may lead to lower personal stigma. Longitudinal studies are needed to learn more about these possibilities. Nevertheless, the large negative association between personal stigma and help seeking, as compared with the insignificant association between perceived stigma and help seeking, is highly suggestive that personal stigma is a more prominent barrier.

This line of thought begs two questions: (a) Should we stop worrying about perceived public stigma as a barrier to help seeking? and (b) If personal stigma is the more prominent barrier, how can interventions reduce it?

Regarding the first question, one should keep in mind that previous findings are mixed regarding perceived stigma as a barrier to help seeking, as reviewed earlier. 
The findings may be highly dependent on the context. For example, awareness of public stigma may be less likely to impede help seeking if, for example, people are confident that their treatment will remain confidential. Also, people may be less concerned about the attitudes of "most people" than the attitudes of important individuals in their lives, such as significant others, family, and close friends. In addition, reducing perceived public stigma may have an indirect effect on help seeking by leading to a reduction in personal stigma (as in the sequential process proposed by Corrigan et al., 2006), which in turn increases help seeking. As noted earlier, one promising approach to reducing perceived public stigma among students, in light of our findings, would be a social norms campaign. Yet another possible approach would be to attempt to reduce stigma among faculty and staff, with the aim of reducing students' perceived stigma among those personnel. This may be particularly valuable in view of our finding that perceived stigma is associated with a lower reported likelihood of students' talking to faculty or staff about mental health problems affecting academic performance. Further research is needed to determine the extent to which these types of interventions can actually reduce perceived stigma and whether lower perceived stigma would translate to lower personal stigma and increased help seeking. Finally, as noted earlier, even if it does not substantially increase help-seeking behavior, reducing perceived stigma is likely to improve the self-esteem and psychological well-being of people with mental disorders (as suggested by our finding that depressive symptoms were positively associated with perceived stigma).

The second question is how to reduce personal stigma, given that it appears to be a significant barrier to help seeking. Previous research suggests that education and social contact are promising approaches to reduce personal stigma, although little is known about whether these approaches actually translate into increased help-seeking behavior (Corrigan, 2004). A small number of interventions appear promising for younger populations in particular. Pinfold et al. (2003) found that a school-based program combining education and social contact with people with mental illness was associated with improvements in stigmatizing attitudes among adolescents 6 months later. O'Kearney, Gibson, Christensen, and Griffiths (2006) found that an Internet-based cognitive behavioral therapy program reduced stigmatizing attitudes among adolescent men. This latter approach seems especially promising in college populations because of students' frequent use of the Internet and the fact that Internet-based approaches for college students have shown psychological benefits for other mental health issues such as eating disorders (Taylor et al., 2006). As noted above, future research on any of these approaches will need to evaluate whether interventions affect not only reported attitudes but also actual help-seeking behavior.

It is important to interpret this study's findings in light of the specific population. As discussed in the introduction, college students have special significance for 
mental health policy as they represent a large proportion of people who are at an age when mental disorders often have first onset and may have lasting implications if not treated properly. At the same time, a number of factors suggest caution when thinking about how our findings may generalize to other populations. First, although college students have a similar overall prevalence of mental disorders as same-aged noncollege students, the prevalence of severe mental illness such as bipolar disorder is lower (Blanco et al., 2008). Second, most college students are late adolescents or young adults, and many of them are early in the process of developing and recognizing emergent symptoms of mental disorders. In addition, they are typically undergoing a number of developmental processes, such as establishing a separate identity from parents and family, which could cause their attitudes about mental disorders to evolve rapidly. Finally, in the college campuses in our sample, as at many other campuses, the financial barriers to mental health services are reduced, with at least some level of free or highly subsidized services available to all students. In theory, lower financial barriers may encourage favorable attitudes about services (if students conclude that the school is supportive of services) or at least increase the relative importance of attitudinal factors (by diminishing financial factors).

\section{Conclusions}

Our findings suggest that stigma reduction efforts are more likely to increase help-seeking behavior among college students if they reduce personally held stigmatizing attitudes as opposed to perceptions of what others believe. This represents an opportunity and a challenge as interventions to date have had limited success in making lasting changes to people's attitudes about mental illness (Corrigan, 2004). In addition, our findings indicate that stigmatizing attitudes vary significantly across subgroups within college populations, which suggests that stigma-reduction efforts may be more effective if strategies are tailored accordingly.

\section{Appendix Stigma Items in the Questionnaire}

\section{Perceived public stigma}

Please indicate whether you agree or disagree with the following statements.

1. Most people would willingly accept someone who has received mental health treatment as a close friend.

2. Most people believe that a person who has received mental health treatment is just as intelligent as the average person. 


\section{Appendix (continued)}

3. Most people believe that someone who has received mental health treatment is just as trustworthy as the average person.

4. Most people would accept someone who has fully recovered from a mental illness as a teacher of young children in a public school.

5. Most people feel that receiving mental health treatment is a sign of personal failure.*

6. Most people would not hire someone who has received mental health treatment to take care of their children, even if he or she had been well for some time.*

7. Most people think less of a person who has received mental health treatment.*

8. Most employers will hire someone who has received mental health treatment if he or she is qualified for the job.

9. Most employers will pass over the application of someone who has received mental health treatment in favor of another applicant.*

10. Most people in my community would treat someone who has received mental health treatment just as they would treat anyone.

11. Most young adults would be reluctant to date someone who has been hospitalized for a serious mental disorder.*

12. Once they know a person has received mental health treatment, most people will take that person's opinions less seriously.*

\section{Personal stigma}

Please indicate whether you agree or disagree with the following statements.

1. I would willingly accept someone who has received mental health treatment as a close friend.

2. I would think less of a person who has received mental health treatment.*

3. I believe that someone who has received mental health treatment is just as trustworthy as the average person.

Note: Answer choices for each item are: $0=$ strongly agree, $1=$ agree, $2=$ somewhat agree, 3 somewhat disagree, $4=$ disagree, $5=$ strongly disagree. Items were adapted from the Discrimination-Devaluation scale developed by Bruce Link and colleagues, as described in the methods section. Items with a '*' are reverse-scored-i.e., "Strongly agree" corresponds to 5 points instead of 0 points, and so on. To balance out potential effects of question ordering, participants were randomized such that they had a 50 percent chance of being asked the perceived stigma items before the personal stigma items, and a 50 percent chance of the reverse.

\section{References}

Abe-Kim, J., Takeuchi, D. T., Hong, S., Zane, N., Sue, S., Spencer, M. S., et al. (2007). Use of mental health-related services among immigrant and U.S.-born Asian Americans: Results from the National Latino and Asian American Study. American Journal of Public Health, 97, 91-98.

Anglin, D. M., Alberti, P. M., Link, B. G., \& Phelan, J. C. (2008). Racial differences in beliefs about the effectiveness and necessity of mental health treatment. American Journal of Community Psychology, 42, 17-24.

Barney, L. J., Griffiths, K. M., Jorm, A. F., \& Christensen, H. (2006). Stigma about depression and its impact on help-seeking intentions. Australian and New Zealand Journal of Psychiatry, 40, 51-54. 
Blanco, C., Okuda, M., Wright, C., Hasin, D. S., Grant, B. F., Liu, S., et al. (2008). Mental health of college students and their non-college-attending peers: Results from the National Epidemiologic Study on Alcohol and Related Conditions. Archives of General Psychiatry, 65, 1429-1437.

Breslau, J., Lane, M., Sampson, N., \& Kessler, R. C. (2008). Mental disorders and subsequent educational attainment in a US national sample. Journal of Psychiatric Research, 42, 708-716.

Cooper, A. E., Corrigan, P. W., \& Watson, A. C. (2003). Mental illness stigma and care-seeking. Journal of Nervous and Mental Disease, 191, 339-341.

Corrigan, P. W. (2004). How stigma interferes with mental health care. American Psychologist, 59, $614-625$.

Corrigan, P. W., Watson, A. C., \& Barr, L. (2006). The self-stigma of mental illness: Implications for self-esteem and self-efficacy. Journal of Social and Clinical Psychology, 25, 875-884.

Eisenberg, D., Golberstein, E., \& Gollust, S. E. (2007). Help-seeking and access to mental health care in a university student population. Medical Care, 45, 594-601.

Ettner, S. L., Frank, R. G., \& Kessler, R. C. (1997). The impact of psychiatric disorders on labor market outcomes. Industrial and Labor Relations Review, 51, 64-81.

Galea, S., \& Tracy, M. (2007). Participation rates in epidemiologic studies. Annals of Epidemiology, 179, 643-653.

Golberstein, E., Eisenberg, D., \& Gollust, S. E. (2008). Perceived stigma and mental health care seeking. Psychiatric Services, 59, 392-399.

Griffiths, K. M., Christensen, H., Jorm, A. F., Evans, K., \& Groves, C. (2004). Effect of Web-based depression literacy and cognitive-behavioural therapy interventions on stigmatising attitudes to depression: Randomised controlled trial. British Journal of Psychiatry, 185, 342-349.

Groves, R. M. (2006). Nonresponse rates and nonresponse bias in household surveys. Public Opinion Quarterly, 70, 646-675.

Hogan, M. F. (2003). New Freedom Commission Report: The President's New Freedom Commission: Recommendations to transform mental health care in America. Psychiatric Services, 54, 1467.

Jorm, A. F., Medway, J., Christensen, H., Korten, A. E., Jacomb, P. A., \& Rodgers, B. (2000). Attitudes towards people with depression: Effects on the public's help-seeking and outcome when experiencing common psychiatric symptoms. Australian and New Zealand Journal of Psychiatry, 34, 612-618.

Kessler, R. C., Berglund, P. A., Bruce, M. L., Koch, J. R., Laska, E. M., Leaf, P. J., et al. (2001). The prevalence and correlates of untreated serious mental illness. Health Services Research, 36(6, Pt. 1), 987-1007.

Kessler, R. C., Berglund, P., Demler, O., Jin, R., Merikangas, K. R., \& Walters, E. E. (2005). Lifetime prevalence and age-of-onset distributions of DSM-IV disorders in the National Comorbidity Survey Replication. Archives of General Psychiatry, 62, 593-602.

Kessler, R. C., Walters, E. E., \& Forthofer, M. S. (1998). The social consequences of psychiatric disorders, III: Probability of marital stability. Amercian Journal of Psychiatry, 155, 1092-1096.

Link, B. G. (1987). Understanding labeling effects in the area of mental disorders: An assessment of the effects of expectations of rejection. American Sociological Review, 52, 96-112.

Link, B. G., Cullen, F., Struening, E., Shrout, P., \& Dohrenwend, B. (1989). A modified labeling theory approach to mental disorders: An empirical assessment. American Sociological Review, 54, 400-423.

Mechanic, D. (1966). Response factors in illness: The study of illness behavior. Social Psychiatry, 1, 11-20.

Mojtabai, R. (2007). Americans' attitudes toward mental health treatment seeking: 1990-2003. Psychiatric Services, 58, 642-651.

Mojtabai, R., Olfson, M., \& Mechanic, D. (2002). Perceived need and help-seeking in adults with mood, anxiety, or substance use disorders. Archives of General Psychiatry, 59, 77-84.

National Center for Education Statistics. (2008a). Digest of Education Statistics. Retrieved April 17, 2009, from http://nces.ed.gov/Programs/digest/

National Center for Education Statistics. (2008b). Integrated Postsecondary Education Data System (IPEDS). Retrieved June 6, 2008, from http://nces.ed.gov/ipeds/

Nederhof, A. J. (1985). Methods of coping with social desirability bias: A review. European Journal of Social Psychology, 15, 263-280. 
Ojeda, V. D., \& Bergstresser, S. M. (2008). Gender, race-ethnicity, and psychosocial barriers to mental health care: An examination of perceptions and attitudes among adults reporting unmet need. Journal of Health and Social Behavior, 49, 317-334.

Ojeda, V. D., \& McGuire, T. G. (2006). Gender and racial/ethnic differences in use of outpatient mental health and substance use services by depressed adults. Psychiatric Quarterly, 77, 211-222.

O'Kearney, R., Gibson, M., Christensen, H., \& Griffiths, K. M. (2006). Effects of a cognitive-behavioural internet program on depression, vulnerability to depression and stigma in adolescent males: A school-based controlled trial. Cognitive Behaviour Therapy, 35, 43-54.

Penn, D. L., Judge, A., Jamieson, P., Garczynski, J., Hennessy, M., \& Romer, D. (2005). Treating and preventing adolescent mental health disorders: What we know and what we don't know. New York: Oxford University Press with the Annenberg Foundation Trust at Sunnylands and the Annenberg Public Policy Center at the University of Pennsylvania.

Phelan, J. C., Link, B. G., Stueve, A., \& Pescosolido, B. A. (2000). Public conceptions of mental illness in 1950 and 1996: What is mental illness and is it to be feared? Journal of Health and Social Behavior, 41, 188-207.

Pinfold, V., Toulmin, H., Thornicroft, G., Huxley, P., Farmer, P., \& Graham, T. (2003). Reducing psychiatric stigma and discrimination: Evaluation of educational interventions in UK secondary schools. British Journal of Psychiatry, 182, 342-346.

Porter, S. R., \& Umbach, P. D. (2006). Student survey response rates across institutions: Why do they vary? Research in Higher Education, 47, 229-247.

Rickwood, D., Deane, F. P., Wilson, C. J., \& Ciarrochi, J. (2005). Young people's help-seeking for mental health problems. Australian e-Journal for the Advancement of Mental Health, 4, 1-34.

Shea, M., \& Yeh, C. J. (2008). Asian American students' cultural values, stigma, and relational selfconstrual: Correlates of attitudes toward professional help seeking. Journal of Mental Health Counseling, 30, 157-172.

Sirey, J. A., Bruce, M. L., Alexopoulos, G. S., Perlick, D. A., Friedman, S. J., \& Meyers, B. S. (2001). Stigma as a barrier to recovery: Perceived stigma and patient-rated severity of illness as predictors of antidepressant drug adherence. Psychiatric Services, 52, 1615-1620.

Sirey, J. A., Bruce, M. L., Alexopoulos, G. S., Perlick, D. A., Raue, P., Friedman, S. J., et al. (2001). Perceived stigma as a predictor of treatment discontinuation in young and older outpatients with depression. American Journal of Psychiatry, 158, 479-481.

Spitzer, R. L., Kroenke, K., \& Williams, J. B. (1999). Validation and utility of a self-report version of PRIME-MD: The PHQ primary care study. JAMA: The Journal of the American Medical Association, 282, 1737-1744.

Taylor, C. B., Bryson, S., Luce, K. H., Cunning, D., Doyle, A. C., Abascal, L. B., et al. (2006). Prevention of eating disorders in at-risk college-age women. Archives of General Psychiatry, 63, 881-888.

U.S. Department of Health and Human Services. (1999). Mental health: A Report of the Surgeon General. Rockville, MD: National Institute of Mental Health.

Wang, P. S., Berglund, P., Olfson, M., Pincus, H. A., Wells, K. B., \& Kessler, R. C. (2005). Failure and delay in initial treatment contact after first onset of mental disorders in the National Comorbidity Survey Replication. Archives of General Psychiatry, 62, 603-613.

Wang, P. S., Lane, M., Olfson, M., Pincus, H. A., Wells, K. B., \& Kessler, R. C. (2005). Twelve-month use of mental health services in the United States: Results from the National Comorbidity Survey replication. Archives of General Psychiatry, 62, 629-640.

Wechsler, H., Nelson, T. F., Lee, J. E., Seibring, M., Lewis, C., \& Keeling, R. P. (2003). Perception and reality: A national evaluation of social norms marketing interventions to reduce college students' heavy alcohol use. Journal of Studies on Alcohol, 64, 484-495.

Wells, K., Sturm, R., \& Burnam, M. A. (2003). Healthcare for Communities Household Survey public use files: Revised codebook. Ann Arbor, MI: ICPSR.

Zhang, N., \& Dixon, D. N. (2003). Acculturation and attitudes of Asian international students toward seeking psychological help. Journal of Multicultural Counseling and Development, 31, 205-222. 